\title{
METHODOLOGICAL BRICOLAGE: A JOURNEY ON THE ROAD LESS TRAVELED IN TOURISM STUDIES
}

\author{
MICHAEL O’REGAN \\ Faculty of Management, Bournemouth University, Poole, Dorset, UK
}

\begin{abstract}
This article, by exploring an approach to research, argues a case for bricolage as an acceptable approach in tourism research. Tourism researchers thinking about utilizing methodological bricolage as a research approach have little scholarly literature to draw from; therefore, it remains relatively underused and misunderstood as a means of qualitative inquiry. This article presents an account of getting to grips with a multiparadigmatic methodological bricolage as a way of understanding the world of backpacking and its inhabitants, who actively constitute, distinguish, and label themselves as backpackers. It is an approach that delivered a coherent conceptual scaffold, producing a rich, but always partial, understanding of a social world, those who inhabit it, and how they sustain it. It doing so, the research design adds to methodological innovation and diversification in tourism research.
\end{abstract}

Key words: Bricolage; Research design; Backpacking; Tourism; Mobilities

\section{Introduction}

Tourism research has primarily relied on established research methods rooted in the positivist and postpositivist traditions (Guthrie, 2007; Riley \& Love, 2000), but the indeterminate, messy, ambiguous nature of tourism often overwhelms both quantitative and qualitative researchers, with tourism ethnographic research often obscuring as much about phenomena as they expose (O’Gorman, MacLaren, \& Bryce, 2012). Research on specific tourism movements often reveals little about how movement is lived, practiced, performed, enabled, mobilized, enacted, sustained, manipulated, regulated, contextualized, and governed, with Law (2004) arguing that when social science tries to describe things that are complex, diffuse and messy, it tends to make a mess of it. He argues that standard methods are often extremely good at what they set out to do, but they are often not appropriate to study the ephemeral, the elusive, the indefinite, the subjective, and the irregular. He argues that we need to "teach ourselves to know some of the realities of the world using methods unusual to or unknown in social science” (p. 2).

A developing mobilities paradigm (Sheller \& Urry, 2006) has come to illuminate some of the messy intersecting mobilities of capital, knowledge, 
ideas, danger, information, and bodies that constitute and have enabled specific movements by questioning the processes by which distinct forms of tourism emerge, and how they express themselves as flows, lifestyles, or mobility cultures, with recent studies establishing the sociospatial practices (i.e., signifying practices, often corporeal and embodied, are often coded to a particular role or lifestyle) of those who travel from organic farm to farm, new age travelers, pilgrims, cyclists, recreational vehicle owners to musicians and hitchhikers (Jensen, 2009; Nóvoa, 2012; O’Regan, 2012). These movements were found to have formed through all kinds of interlocking practices, meanings, experiences, stories, feelings, aspirations, systems, affects, ambiences, atmospheres, encounters, interactions, infrastructures, regulations, institutions, roles, governance, habits, assemblages, expectations, anticipations, and memories. However, the complexity and richness of spatial movements challenge researchers to "keep up." Among the ever changing and pervasive nature of new forms of (im)mobility-especially within the specificity, context, and politics of particular forms of movement-are backpackers. Their mobility performances, with their "active and affective interventions in a world of relations and movements" (McCormack, 2005, p. 122), remain elusive and difficult to articulate. This article argues, through a clear example, that tourism researchers creating a research design suited to the richness and often elusive nature of tourism mobilities should explore alternative methodologies such as methodological bricolage.

\section{Backpacking}

One particular form of tourism characterized by extensive spatial mobility is backpacking, wherein budget independent travelers (backpackers), possessing time and space flexibility and often traveling for up to 1 year (Berdichevsky, Poria, \& Uriely, 2013), move from place to place. Made up of geographically dispersed individuals, but sharing sociospatial imaginaries and practices that are generative of intrinsic signifying meaning, their global spread and scope has been objectively established, with various overlapping definitions field tested through empirical research. Attempts to establish a ground of "objective phenomena" have been primarily through traditional academic methodologies such as ethnography, and have brought new articulations by way of taxonomies, segments, and typologies. While state-of-the-art ethnographic research, often worked within single disciplines, has moved backpacking beyond common tropes, enlarging the "community of discourse" (e.g., by articulating backpacker motivations), they often reveal little about how backpacking is practiced, performed, mobilized, sustained, and manipulated within a complex, interconnected system. I do not argue for the abandonment of traditional academic methodologies in the study of backpacking, with recent rich ethnographic studies, for example, finding that the desire to have sex is an important motivator for engaging in certain experiences (Berdichevsky et al., 2013). However, the community of discourse is engendered because the phenomenon is only partially amenable to conventional methodologies given the specific situational nature of many individual studies (Tribe, 2006), with gaps and weaknesses in methodologies pointing to undiscovered riches of human experiences behind the label "backpacker."

While conventional methodologies have provided a bank of valuable data about backpacking, which continues to generate rich insight, findings have not been consistent and replicable over time, with variations in population coverage, definitions, and classification procedures (Van Egmond, 2007). I sought as part of a doctoral journey to engage in a more curious, open-ended, engaged exploration of a phenomenon that often evades a purely ethnographic articulation with specific research questions, individual cases, or a conventional validated set of prespecified procedures. While these procedures provide the distance of objectivity by routinely selecting interviewees based on a priori order (age, length of journey, accommodation type usage), and reduce insecurity, they run the possibility of destroying the encounter itself. Seeking an "ontic depth" so as to understand backpacker movement as lived experience remains a comparatively neglected area of research in tourism studies (Franklin, 2003), its construction in everyday life as a mode of being evading articulation in the literature. I sought to untangle and clarify backpacking's complex nature, and understand backpacking's recognizable coherence reproduces (maintaining 
coherence and stability through time-space) and contributes to a world that offers particular forms of seeing, encounter, togetherness, and sociality that mapped onto alternative spaces and networks of mobility. I decided on an ethnographic and qualitative approach that was naturalistic, relying on constructivism and interpretivism as a general philosophic approach. To feel their world from an ethnographic perspective and get closer to representing their social world as it really was, I wanted to stress the human experience of the subjects under inquiry by "getting inside" and grappling with the complexity of everyday experiences that take shape and gain bodily expression in their world.

\section{Feeling Mobility}

Any approach that is ontologically relativist and epistemologically subjectivist can reshape the researcher, requiring him or her to go beyond the surface, searching for and questioning tacit meanings relating to movement, representations, and practice. Often unacknowledged in tourism ethnographic research (O’Gorman et al., 2012), (social) worlds are socially constructed and always in a process of becoming. Backpacking is a world one can see, feel, touch, and smell, but only through one's embodied mobility and participation that yields encounters with a world with its own logic, agents, institutions, and capital. To uncover this world and its inhabitants is not as simple as interviewing backpackers or visiting a backpacker destination, with those who enter this world enacting it "at every instant in the movement of existence" (MerleauPonty, 1945/1962, p. 89). Lived bodies become caught in its fabric, with claims for a new subjectively generating practices that leave "traces of varying degrees of solidity, opacity or permanence" (Shanks \& Tilley, 1992, p. 131). I believed that by participating in patterns of movement as a form of sustained immersive engagement and interviewing backpackers could reveal the competencies, skills, and knowledge to feel at ease and get ahead in this world, and therefore how this world is constructed and reproduced.

Within 2 weeks of a 6-month field trip in South America traveling overland on a backpacker route from Rio de Janeiro to Cusco via Manaus, Iquitos and La Paz, I became increasingly concerned about revealing my true self by setting aside my backpacker role and renegotiating my relationship with interviewees through the role of interviewer. It meant that I was no longer immersed-my questions breaching the world of those that I chose to interview. As my professional credentials were presented, subjects clammed up, becoming defensive, using the opportunity for self-construction and selecting which truths to convey. In addition, because practices are about the ways things are or the way "we do things" and are not spelled out or written down, more experienced and knowledgeable backpackers found verbal explanations "superfluous," except if such explanations are directed at "newcomers" (Johnson, 2008). As I alternated my researcher perspective with the perspective of those interviewed, their accounts were often ambiguous and even misleading, with significant differences between what I observed and what they said they did. They often downplayed violations of the any practices deemed inappropriate to the ideal form and type characteristics of backpacking (Uriely, 2009). My role as researcher was considered a form of "symbolic violence” (Bourdieu, 1977), which rapidly used up “interview rapport” (Garfinkel, 1967/1984, p. 113). When I developed a second approach and downplayed my research, the interviewees assumed that my research was a "scam" (Lozanski \& Beres, 2007), which undermined my status as a competent researcher. Goffman (1961) described a "discrepant role," which brings a person into a social establishment under a false guise. In both cases, respondents utilized me as an object to shape their identity and performance by either being playful or hostile to academic scrutiny (Davidson, 1999; Edensor, 1998), with Thrift (1994) noting how we cannot extract a representation of the world if those interviewed are "slap bang in the middle of it" (pp. 296-297). As the noting of events, feelings, stories, and conversations through unplanned encounters became more important than "interviews," I was thrown into confusion over the problem of identifying and selecting an appropriate methodology.

Rather than seek to superimpose a rigid academic criteria or agenda on the research process or implement any controls on the fieldwork, I sought to continue the inquiry based on my own experience of backpacking, given research is an interactive process shaped by our "personal history, biography, gender, 
social class, race, ethnicity and those of the people in the setting” (Denzin \& Lincoln, 1998, p. 4). As my background (white, European, male, English speaking, heterosexual), cultural capital (posture, look, and a previous 14-month travel experience as a backpacker), and "nomadic sensibility for routes and rituals” (D’Andrea, 2006, p. 113) made me "one of them" (Merleau-Ponty, 1945/1962, p. 135), I decided to "feel" their mobility (Thrift, 1994) to gain access to the world. Drawing on multiple methods to observe and participate in their world, I began to use my practical knowledge of backpacking and my "vernacular" familiarity with backpacker language, codes, beliefs, dress, and values of this world, to provide me with the capacity to read, describe, investigate, and articulate the culturally contexted practices and processes that drive their world. This more curious, open-ended, engaged exploration way of seeing, labeled bricolage, sought to uncover new insights more "directly connected to specific contexts, practical forms of analysis that are informed by social theory, and the concreteness of lived situations” (Kincheloe, 2005, p. 345).

Bricolage was introduced by Claude Lévi-Strauss (1966) to enable various paradigms to interbreed and disciplinary and methodological boundaries to dissolve "between the personal and the professional, self and other, theory and experience" (GalaniMoutafi, 2000, p. 216). As a multimethodological approach to qualitative inquiry, my methodological practices were based on notions of emergent design and flexibility; combining (social) constructivist, participatory and interpretive paradigms; appropriating, reinterpreting, and blending ethnography, historiography, cultural studies analysis, ethnomethodology, and grounded theory as well as multiple disciplines (transport studies, human geography, history, sociology). It was an approach that enabled me to "remain sensitive to the data by being able to record events and detect happenings without first having them filtered through and squared with pre-existing hypotheses and biases” (Glaser, 1978, p. 3). Spending 1 year backpacking over three trips with a multisite approach (Marcus, 1995) to capture backpacking behavior in its broad natural context, I incorporated a reflective (thinking) aspect, where the "researcher-as-interpreter bricoleur" (Denzin \& Lincoln, 2000) is "more or less" a participant and "more or less" an observer (Tedlock, 2000).
My position on the continuum was determined by unplanned events, activities, practices, and encounters as I bodily traveled with and among primarily Western, English-speaking backpackers (Sorensen, 2003); sometimes "actors of our own roles, supporting actors in the performance of others, and at other times as part of the audience" but "always an integral part of the myriad of performances taking place around us” (Ateljevic \& Doorne, 2005, p. 178).

While subjugating as much as possible all roles and possible selves except that of backpacker, rather than become wholly and unconsciously detached from a scholastic habitus, it meant not being overly infected with a scholastic point of view. This "engaged detachment" enabled me to keep distance with multiples "selves" and roles to understand "shared experiences, everyday routines, fleeting encounters, embodied movements, precognitive triggers, practical skills, affective intensities, enduring urges, unexceptional interactions and sensuous dispositions" (Lorimer, 2005, p. 84). By "bracketing” (Lynch, 1993) my researcher role, I became sensitive to backpackers and the complexity of their world; bricolage coming to exist "out of respect for the complexity of the lived world" (Kincheloe, 2004, p. 131) and an understanding "that there is far more to the world than what we can see" (Kincheloe, 2005, p. 346). Just as novelist, Hermann Hesse (b. 1877-d. 1962) recognized the thinkers and craftsmen as two sides of the same coin, my stance allowed me to listen, learn, and interact, my "split (scholar-backpacker) habitus” (Bourdieu, 2004, p. 127) stretching my imagination, a creative tension reflecting the contradictory dispositions of backpacking and scholarly life. Following Levi-Strauss, who sought "underlying structures that govern human meaning-making" (Rogers, 2012, p. 2), I entered into a dialogue with the fragmented resources I had collected, and sought to assemble them into an emergent arrangement that would extend the knowledge of backpacking beyond situated accounts, but resisting ideal, preconceived solutions or conclusions.

\section{Pulling it Together}

I had a "vulgar competence” (Garfinkel \& Wieder, 1992) with backpacking and had gathered fragmented pieces and resources from participation, field notes, practices, photos, ideas, literary texts, popular 
media, notes, observations, interviews, blog entries (blogging 3,000 entries on www.nomadx.org), performances, stories, conversations, fiction, and the daily discursive reality of backpackers that usually remain hidden and unconscious even to the subject, but reconstructable to the researcher. Employing bricolage helped me move into a new, more complex, domain of knowledge production, becoming "far more conscious of multiple layers of intersections between the knower and the known, perception and the lived world, and discourse and representation" (Kincheloe, 2001, p. 686). I began deciphering and connecting isolated pieces with other apparently isolated pieces, connecting parts to the whole, more interested in how things "go together" rather than in their inner properties. By stitching pieces together in a pragmatic and self-reflective way so as to contextualize and conceptualize different aspects of the world and work outwards towards the discovery of new truths (Hollinshead, 1999), the bricoleur becomes a “quilt maker" (Denzin \& Lincoln, 2005). Employing multiple strategies, different and often competing interpretive practices and theories, the bricoleur seeks out and piece together sets of observed and encountered practices and performances to make a solution to a puzzle.

I confronted backpacking through the lens of an interpretive perspective in order "to see beyond the literalness of the observed" and move "to a deeper level of data analysis as he or she sees 'what's not there' in physical presence, what is not discernible by the ethnographic eye" (Kincheloe, 2001, p. 686). Each phase of "field" research was followed by interpretation and intensive introspection and (self) reflection, my participatory encounters when I saw and felt backpacking as natural, giving way to an interpretative stance when I stepped back. After being engrossed and immersed, stepping back "put distance” (M. Richardson, 1980, p. 217) between me and the phenomenon. Critical distance emerges as the researcher "returns home to make sense" of the research (Grossberg, 1989, p. 23), where "back in the recesses of his mind, he asks in a whisper, almost as if he were afraid: What does it all mean?” (M. Richardson, 1980, p. 221). Writing in particular was central to my journey, helping to fashion "meaning and interpretation” (Denzin, 2009, p. 34); writing itself became a form of inquiry (L. Richardson, 1995) as I weaved together sets fragmented pieces, hoping to connect to all aspects of the collected resources and give it coherence.

Seeking to "develop complex concepts, construct alternate modes of reasoning, and produce unprecedented interpretations of . . . data” (Kincheloe, 2005, p. 339), bricoleurs see "different ways of making sense, and pragmatic solutions that are not degraded by their pragmatism” (Kincheloe, 2005, p. 326). Over the course of 12 months, I sought to apply various conceptual theories, and looked at not only to general theories of tourism, but various models and heuristic tools that could capture the complexity of the world I had observed and participated in. I entered into a "dialogue" with a variety of conceptual maps, by threading the collected resources, fragments, and pieces through them to make previously repressed features of the social world visible. Rather than a rational and deliberate process, Rüling and Duymedjian (2014) note that bricolage proceeds through "processes of permutation and substitution, trial and experimentation" (p. 99). From anthropological theories of globalization (Appadurai, 1990), actor-network theory (Callon, 1999), the theory of collective action (Olson, 1971), ability theory of practice (Giddens, 1984), worldmaking (Goodman, 1978), serious leisure (Stebbins, 1982), leisure involvement (Havitz \& Dimanche, 1997), the travel career trajectory (Pearce, 1988), de Certeau's (1988) theory of everyday practices, the theory of cosmopolitanization (Beck, 2000), social world theory (Unruh, 1980), and Garfinkel and Wieder's (1992) theory of practice to assemblage theory (Deleuze, 1992), I sought to apply various conceptual theories that could contribute to a understanding of the ontological character of backpacking.

\section{A Partial and Situated Bricolage}

A conversation with Pierre Bourdieu began when I was threading various pieces through Bourdieu's "theory of the art of practice" (de Certeau, 1988, p. 43), creating an emergent and unpredictable arrangement that reassembled Bourdieusian concepts, so as to articulate an assemblage of concepts in the form of an impure theory that created a new way to explain the human drama, contradictions of a complex, interconnected system. Using the Bourdieusian concepts of habitus, capital, and field allowed me to draw from diverse practices, 
conversations, observations, and field data, with his concepts acting as a form of glue that offered an explanation for a social world where "practices emerge and (re)make the world that makes them" (Wacquant, 2005, p. 136). Reworking Bourdieusian concepts allowed me to delve deeper, investigating the conscious and beyond conscious repetitive, beliefs, norms, forces, meaningful relationships, practices, and performances that set the pace and pattern of interrelations among backpackers and constitutes their sense of the world, even though members are often unaware of many of the values that bind them together or are unable to verbalize them. My account of backpacking generated a composite, but partial, picture of a phenomenon, where conscious (and beyond conscious) forms of desire, motivation, belief, and action can lead an individual to redraw boundaries in their life, their search for new openings, beginnings, rhythms, or possibilities propelling them towards an world that promises, but also demands, so much.

I argue Bourdieu's concept of habitus can be applied as a secondary socialization, a (Western) backpacker habitus emerging not within a relatively bounded locality but through embodied and perceptual engagement with travelerscapes (scapes) in which they seek distinction. Changing life circumstances and limited forms of discontinuity enables geographically dispersed individuals to enact, perform, and combine mobility into a new set of dispositions of being, seeing, acting, and thinking that enable them to navigate landscapes of mobility and practice successfully. By illustrating how participants get a feel for the "game" through a secondary socialization, I illustrate how backpackers learn competencies, skills, knowledge, and the capacity to move both socially, temporally, and spatially the "right" way by engaging in a "learning trajectory" (Wenger, 1998). While each backpacker has a unique learning trajectory and "apprenticeship of observation” (Lortie, 1975), backpackers become active participants and creators of the discourse used in a field that is historically and socially situated.

I also argue there is a continuum between strategic and tactical positions within the scapes; disparate points on a continuum on which we can find discrete gradations or depth and breath. Backpackers, I found, are locked into relations of conflict and cooperation, as they constantly renegotiate and rework their relations, not merely searching for authenticity of the Other, but searching the authenticity of, and between, themselves Those starting their journey incorporate a habitus that is strategic in the way it develops, is demonstrated and communicated, and acted upon, the socialization process initially fastening the subject firmly to social structures (to the world provided), generating practices and performances that have a visible coherence. Accumulated capital over time-space serves as a resource for more "grounded" action meaning, as newly internalized dispositions become partially incorporated into an individual's subjectivity. As the scapes get "under the skin," each new encounter and experience provides new learning opportunities and reflexivity that soon demands some reinterpretation of the role, the enthusiasm in which they seek capital not without reflection. While reflexivity or cognitive reflection is initially used to grasp the objectified world, the accumulation of (embodied) (sub)cultural capital enable individuals to act with a deeper knowledge and understanding of the scapes, its boundaries, and their position in it.

While strategic backpackers tend to misrecognize the scapes as an external, naturally given world, I argued that tactical backpackers recognize the scapes as a game and deem it worthy of struggle. These backpackers see a range of visible tactical options and opportunities available as they travel, their performance affirming their authentic self and their "superior" position to themselves and others. Tactical backpackers seek to mobilize their competencies, knowledge, and skills to struggle against labeling and ascribed discourses as they utilize cracks and opportunities, while those with a strategic intent initially seek out other backpackers, routes, and infrastructure. They stick to the center of the scapes and pour themselves into "the backpacker role.” A tactical stance becomes very visible when a more reflexive backpacker feels a lack of fit between the habitus (feel for the game) and field (the game itself), without it actually constituting a break from the game or the role. A tactical stance is an ongoing script and comes about after much travel experience and reflexivity, their embodied capital manifesting itself as (economic, cultural, social) skills, abilities, knowledge, and competencies that are put to use in the scapes in which they are embedded. This capital helps them to maneuver with naturalness and ease 
within the scapes and its implicitly agreed logic of what it takes to be a real traveler.

Those who develop a tactical stance can demonstrate it by undertaking shortcuts and roundabout paths — so as to define and individualize their presence within the scapes, performing it to the point where it flows seamlessly from them, bodily and linguistically without any apparent effort or forethought. I argue they are not better backpackers, simply because of their more reflexive way of seeing, or because they seek to create their own trajectories or pathways if given such affordances. However, I argued their tactical interventions shape or contest the scapes boundaries. I found that interplay (encounters of conflict and collaboration) is central to backpacking, since the habitus must be shared, or at least be understood and accepted by all the other actors in the game. While the more tactical traveler will feign the position of the resistant, independent, autonomous, down-to-earth "traveler" who can seek recourse in ambivalence, self-organization, self-reliance, and uncertainty, their victories must be ultimately communicated, feeding back into the scapes through myths, gossip, and stories allowing for the continual reproduction and rejuvenation of the scapes.

\section{Limitations}

There is the issue as to whether the bricolage over theorizes-conceptualizes issues at the expense of a solid, empirically based assessment with internalexternal validity, reliability and objectivity. Given that the bricoleur's perspective mediates all interpretation, critics argue that such research is thus laden with presuppositions, values, and biases, given bricolage largely rests upon the researcher's confidence in self-auditing observations, encounters, and practices. However, recent analysis shows similar issues in tourism ethnographic research, with O'Gorman et al. (2012) noting it is inevitably skewed by the researcher. Hammersley (1999) goes further and suggests that mixing and binding competing and dissimilar theoretical and methodological perspectives is a sign of impurity, leading to an incoherent whole. However, bricolage avoids one-sidedness and partial vision by learning "how to employ a variety of perspectives and interpretations in the service of knowledge” (Nietzsche, 1969, p. 119), with Denzin and Lincoln (1998) noting that "the combination of multiple methods, empirical perspectives and observers in a single study is best understood, then, as a strategy that adds rigor, breadth, and depth to any investigation” (p. 4). I agree there is on-going suspicion of approaches such as mine given the researcher's fidelity to procedure cannot simply be “checked off and certified” (Kincheloe, 2001), my work "vulnerable to dismissal and to trivialization as commonplace" (L. Richardson, 1993, p. 705) as I make no attempt to attach notions pertaining to reliability and (internal and external) validity.

Given I had no hypotheses to confirm or disprove, the constant data comparison, writing, and reflection, later encompassing literature to look for convergent evidence from different sources progressed slowly and organically. I adopted the concept of crystallization (L. Richardson, 1994), which considers the traditional notion of "validity" as a rigid, fixed, twodimensional object. Using a crystal as a metaphorical description, it assumes that there can be no single or triangulated truth, and instead there are many sides or perspectives. Like a crystal, bricolage expands, mutates, and alters as possibilities are played with, while at the same time reflecting and refracting the "light" of the social world under inquiry. Crystallization embodies the many intricacies inherent in my journey, with the objectivity of a singular truth rejected, with no perfect outcome or "right" answer. The measure of my work is whether "it adds to our knowledge of the world and our understanding of ourselves or enhances life, not whether it follows methodological rules precisely" (Relph, 1981, p. 112). I (partially) capture backpacking's complexity, since new knowledge, while complex and deep, is always a partial and constructed. The work can be evaluated on the researcher's ethical obligation and criteria such as substantive contribution, aesthetic merit, reflexivity, impact, and expression of reality (L. Richardson, 2000).

\section{Researcher Reflections}

Traditional academic methodologies have led to an impressive bank of valuable data and insight about backpacking, but methodologies are sometimes poorly adapted or implemented, with conventional research often resulting in "gaps, silences and misconstructions” (Tribe, 2006, p. 361). The complexity of a social world like backpacking means it 
may be fully studied from outside with researchers who immerse themselves as short-term participants in worlds often become lost, unable to see everyday life in this world as normal and natural, where experiences, emotions, beliefs, and practices may be seen as strange and mysterious. The liberation from seizing each encounter as a potential research subject enabled me to locate backpacking not through a small sample of individual voices at a particular location whose contradictions are explained away by contradictory classifications and various typologies, taxonomies, and segments. From LokerMurphy's (1996) four subgroups of backpackers (escapers/relaxers, social/excitement seekers, selfdevelopers, and achievers) to O’Reilly's (2006) five backpacker types, typologies and segmentation, while addressing backpacking's diversity, may not increase our understanding of how backpackers shape and are shaped by the social world in which they circulate.

The process of bricolage provided a breathing space to make sense of often seemed chaotic and contradictory, enabling new connections between previously unconnected pieces to emerge, uncovering what has been dismissed, deleted, and covered up. In making a variety of previously repressed features of the social world visible, engaging in what might be termed the fictive element of research rather than seek findings, bullet points of knowledge, and the "truth," my construction is not the definitive or authoritative account of backpacking given my interaction was with primarily Western, white, English-speaking, and heterosexual backpackers. Rich ethnographic studies are emerging to "de-center" the Western focus of much backpacker literature and "reclaim epistemological space" for backpackers from Israel, China, Japan, and South Korea. The Israeli backpacker habitus, for example, has integrated Israeli culture, traditions, media, history, military service, and language to develop their own set of dispositions that can be seen as a structural variant of the Western backpacker habitus.

With more mobile tribes, groups, and figurations now "empowered" and more visible than ever before, "self-making” and self-determined life(styles) are leading more people to negotiate new habituses, which may provide individuals with the necessary skills, confidence, and knowledge to traverse and contest fluid, contested, and ever-changing (tourism) landscapes. While on the surface this article highlights a simple model, it adds to methodological innovation and diversification in tourism research, and adds a new layer to our understanding of "mobile methods" and forms of inquiry, explanation, and engagement in mobilities research (Büscher \& Urry, 2009). It accounts for how global flows of people, images, information, knowledge, norms, technologies, and capital have become the building blocks of emerging social worlds. However, the approach, given it involves a significant degree of introspection and reflexive consideration, requires sufficient time to understand the knowledge bases from which particular modes of research emanate and the many unplanned encounters that may shake understanding of a world's points of reference. As researchers and universities come under financial and research output pressure, more standardized timetabled approaches that have been tried and tested may emerge. Kincheloe (2004) feels that becoming a bricoleur is a lifelong process, and I continue to indulge in a longer reflective effort "that the logic of qualitative methodologies is inclined to demand" (Hollinshead, 2004, p. 67), since the bricoleur "always put something of himself in to it” (Lévi-Strauss, 1966, p. 21). I continue to reexamine accepted interpretations by drawing upon backpacking literature, the process of bricolage meaning there was no fear of such literature contaminating, constraining, inhibiting, or stifling, since they interweave within this still emergent study. While I believe the conceptual arrangement "works," in methodological bricolage everything still matters and deserves attention.

\section{Conclusions}

My research journey emerged as a type of creation; its components found, collaged, quilted, cut and pasted, collaborated; sewed; montaged and cobbled together from ideas, notes, observations, interviews, photos, practices, literature, blog entries, stories, and conversations to create something more, something new, based on what I have come to know and continue to learn about backpacking. Addressing the complexity of this world meant crossing disciplines, working within and between competing and overlapping perspectives, paradigms, and methods to focus on shared embodied encounters to pursue new knowledge, while putting aside the order and 
the certainty of old beliefs and the certainty of objectivity. When choosing to listen, observe, participate, and read, the objective was to render explicit what was taken for granted, before stepping back and picking up the pieces of what is left, and sewing them together by engaging in different perspectives, readings, discourses, activities, literature, narratives, stories, concepts, and theories; generating a composite (but evolving and partial) picture of a global phenomenon, where conscious (and beyond conscious) forms of desire, motivation, belief, and action can lead to collectively held patterns of feeling, thinking, and acting emerge, which over time and space can become strongly held dispositions of the mind and body; a practical logic and a way of seeing and doing.

However partial and incomplete, the journey existed out of respect for the complexity and context of a lived world, an inductive approach ensuring different voices were heard and unplanned encounters acknowledged. Rendering participants' movement and practices as well as representations into a readable conceptual theory appropriate to the social structure, I used Bourdiean theory as a heuristic framework and deconstructive foil. By loosening the shackles that discursively shape our understanding of backpacking, I hope to have added to the body of knowledge. By proceeding in an organic, intuitive fashion, and going as far as to diverge from a formal literature review and findings, I sought to communicated a reflexive collage in writing; one that is internally coherent and externally recognizable. While not the final and correct truth, methodological bricolage can add depth, rigor, and multiplicity to an inquiry, while challenging assumptions, established values, and claims to truth.

\section{Acknowledgment}

This work was supported by the Royal Geographic Society under their Travel Bursary Grant.

\section{References}

Appadurai, A. (1990). Disjuncture and difference in the global cultural economy. Theory, Culture and Society, 7(2), 295-310.

Ateljevic, I., \& Doorne, S. (2005). Tourism as a performance: Enacting backpacker tourism in Fiji. In A. Jaworski \& A. Pritchard (Eds.), Discourse, communication and tourism (pp. 173-198). Clevedon, UK: Channel View Publications.

Beck, U. (2000). What is globalization? Cambridge, UK: Polity Press.

Berdichevsky, L., Poria, Y., \& Uriely, N. (2013). Sexual behavior in women's tourist experiences: Motivations, behaviors, and meanings. Tourism Management, 35, 144-155.

Bourdieu, P. (1977). Outline of a theory of practice (R. Nice, Trans.). Cambridge, UK: Cambridge University Press.

Bourdieu, P. (2004). Esquisse pour une auto-analyse. Paris: Éditions Raisons d'Agir.

Büscher, M., \& Urry, J. (2009). Mobile methods and the empirical. European Journal of Social Theory, 12(1), 99-116.

Callon, M. (1999). Actor-network theory-The market test. In J. Hassard \& J. Law (Eds.), Actor-network theory and after (pp. 181-195). Oxford, UK: Blackwell Publishers.

D'Andrea, A. (2006). Neo-nomadism: A theory of postidentitarian mobility in the global age. Mobilities, 1(1), 95-119.

Davidson, K. J. (1999). Traveller acts: A critical ethnography of backpacker India. Ph.D. dissertation, University of Ulster, Northern Ireland.

de Certeau, M. (1988). The practice of everyday life. Berkeley, CA: The University of Berkeley Press.

Deleuze, G. (1992). Societies of control. October, 59, 3-7.

Denzin, N. (2009). The research act in sociology: A theoretical introduction to sociological methods. Piscataway, NJ: Transaction Publishers.

Denzin, N. K., \& Lincoln, Y. S. (1998). Entering the field of qualitative research. In N. K. Denzin \& Y. S. Lincoln (Eds.), The landscape of qualitative research. Theories and issues (pp. 1-34). Thousand Oaks, CA: Sage.

Denzin, N. K., \& Lincoln, Y. S. (2000). Introduction: The discipline and practice of qualitative research. In N. K. Denzin \& Y. S. Lincoln (Eds.), Handbook of qualitative research (2nd ed., pp. 1-28). London: Sage.

Denzin, N. K., \& Lincoln, Y. S. (2005). The Sage handbook of qualitative research. London: Sage.

Edensor, T. (1998). Tourists at the Taj: Performance and meaning at a symbolic site. London: Routledge.

Franklin, A. (2003). Tourism: An introduction. London: Sage.

Galani-Moutafi, V. (2000). The self and the other: Traveler, ethnographer, tourist. Annals of Tourism Research, 27(1), 203-224.

Garfinkel, H. (1984). Studies in Ethnomethodology. Cambridge, UK: Polity Press. (Original publication 1967).

Garfinkel, H., \& Wieder, D. L. (1992). Two incommensurable, asymmetrically alternate technologies of social analysis. In G. Watson \& S. M. Seiler (Eds.), Text in context: Contributions to ethnomethodology (pp. 175-206). New York: Sage.

Giddens, A. (1984). The constitution of society. Outline of the theory of structuration. Cambridge, UK: Polity Press.

Glaser, B. (1978). Theoretical sensitivity: Advances in the methodology of grounded theory. Mill Valley, CA: Sociology Press. 
Goffman, E. (1961). Encounters. Two studies in the sociology of interaction. Indianapolis, IN: Bobbs-Merrill.

Goodman, N. (1978). Ways of worldmaking. Indianapolis, IN: Hackett.

Grossberg, L. (1989). On the road with three ethnographers. Journal of Communication Inquiry, 13(2), 23-26.

Guthrie, C. (2007). On learning the research craft: Memoirs of a journeyman researcher. Journal of Research Practice, 3(1), Article M1.

Hammersley, M. (1999). Not bricolage but boatbuilding: Exploring two metaphors for thinking about ethnography. Journal of Contemporary Ethnography, 28, 574-585.

Havitz, M., \& Dimanche, F. (1997). Leisure involvement revisited: Conceptual conundrums and measurement advances. Journal of Leisure Research, 29(3), 245-278.

Hollinshead, K. (1999). Tourism as public culture: Horne's ideological commentary on the legerdemain of tourism. International Journal of Tourism Research, 1(4), 267-292.

Hollinshead, K. (2004). A primer in ontological craft: The creative capture of people and place through qualitative research. In J. Phillimore \& L. Goodson (Eds.), Qualitative research in tourism: Ontologies, epistemologies and methodologies (pp. 63-82). London: Routledge.

Jensen, O. B. (2009). Foreword: Mobilities as culture. In P. Vannini (Ed.), The cultures of alternative mobilities: Routes less travelled (pp. 1-20). Aldershot, UK: Ashgate.

Johnson, D. P. (2008). Contemporary sociological theory: An integrated multi-level approach. New York: Springer.

Kincheloe J. L. (2001). Describing the bricolage: Conceptualizing a new rigor in qualitative research. Qualitative Inquiry, 7, 679-692.

Kincheloe, J. L. (2004). Critical pedagogy primer. New York/Oxford: Peter Lang.

Kincheloe, J. L. (2005). On to the next level: Continuing the conceptualization of the bricolage. Qualitative Inquiry, 11(3), 323-350.

Law, J. (2004). After method: Mess in social science research. Abingdon, UK: Routledge.

Lévi-Strauss, C. (1966). The savage mind. Chicago, IL: Chicago University Press.

Loker-Murphy, L. (1996). Backpackers in Australia: A motivation-based segmentation study. Journal of Travel and Tourism Marketing, 5(4), 23-45.

Lorimer, H. (2005). Cultural geography: The busyness of being 'more than representational.' Progress in Human Geography, 29(1), 83-94.

Lortie, D. C. (1975). Schoolteacher, a sociological study. Chicago, IL: University of Chicago Press.

Lozanski, K., \& Beres, M. (2007). Temporary transience and qualitative research: Methodological lessons from fieldwork with independent travelers and seasonal workers. International Journal of Qualitative Methods, 6(2). Retrieved from http://www.ualberta.ca/ iiqm/back issues/6_2/lozanski.htm

Lynch, M. (1993). Scientific practice and ordinary action: Ethnomethodology and social studies of science. Cambridge, UK: Cambridge University Press.
Marcus, G. A. (1995). Ethnography in/of the world system: The emergence of multi-sited ethnography. Annual Review of Anthropology, 24, 95-117.

McCormack, D. (2005). Diagramming practice and performance. Environment and Planning D, 23(1), 119-147.

Merleau-Ponty, M. (1962). Phenomenology of perception (C. Smith, Trans.). London: Routledge and Kegan Paul. (Original publication Phenomenologie de la Perception, 1945)

Nietzsche, F. (1969). The genealogy of morals. New York: Random House.

Nóvoa, A. (2012). Musicians on the move: Mobilities and identities of a band on the road. Mobilities, 7(3), 349-368.

O’Gorman, K. D., MacLaren, A. C., \& Bryce, D. (2012). A call for renewal in tourism ethnographic research: The researcher as both the subject and object of knowledge. Current Issues in Tourism, 17(1), 45-59.

Olson, M. (1971). The logic of collective action: Public goods and the theory of groups (Rev. Ed.). Cambridge, MA: Harvard University Press.

O’Regan, M. (2012). Alternative mobility cultures and the resurgence of hitchhiking. In S. Fullagar, K. Markwell, \& E. Wilson (Eds.), Slow tourism: Experiences and mobilities (pp. 128-142). Wallingford, UK: CABI Publishing.

O’Reilly, C. C. (2006). From drifter to gap year tourist: Mainstreaming backpacker travel. Annals of Tourism Research, 33(4), 998-1017.

Pearce, P. L. (1988). The Ulysses factor: Evaluating visitors in tourist settings. New York: Springer-Verlag.

Relph, E. (1981). Phenomenology. In M. E. Harvey \& B. P. Holly (Eds.), Themes in geographic thought (pp. 99-114). London: Croom Helm.

Richardson, L. (1993). Poetics, dramatics, and transgressive validity: The case of the skipped line. The Sociological Quarterly, 34(4), 695-710.

Richardson, L. (1994). Writing: A method of inquiry. In N. K. Denzin \& Y. S. Lincoln (Eds.), Handbook of qualitative research (pp. 516-529). Thousand Oaks, CA: Sage.

Richardson, L. (1995). Narrative and sociology. In J. Van Maanen (Ed.), Representation in ethnography (pp. 198-221). Thousand Oaks, CA: Sage.

Richardson, L. (2000). Evaluating ethnography. Qualitative Inquiry, 6(2), 253-255.

Richardson, M. (1980). Culture and the urban stage: The nexus of setting, behavior, and image in urban places. In I. Altman, A. Rapoport, \& J. Wohlwill (Eds.), Human behavior and environment: Advances in theory and research. Vol. 4: Environment and culture (pp. 209-241). New York: Plenum Press.

Riley, R. W., \& Love, L. L. (2000). The state of qualitative tourism research. Annals of Tourism Research, 27(1), 164-187.

Rogers, M. (2012). Contextualizing theories and practices of bricolage research. The Qualitative Report, 17, 1-17.

Rüling, C., \& Duymedjian, R. (2014). Digital bricolage: Resources and coordination in the production of digital visual effects. Technological Forecasting and Social Change, 83, 98-110. 
Shanks, M., \& Tilley, C. (1992). Re-constructing archaeology (2nd ed.). Cambridge: Cambridge University Press.

Sheller, M., \& Urry, J. (2006). The new mobilities paradigm. Environment and Planning A, 38(2), 207-226.

Sorensen, A. (2003). Backpacker ethnography. Annals of Tourism Research, 30(4), 847-867.

Stebbins, R. A. (1982). Serious leisure: A conceptual statement. Pacific Sociological Review, 25(2), 251-272.

Tedlock, B. (2000). Ethnography and ethnographic representation. In N. K. Denzin \& Y. S. Lincoln (Eds.), Handbook of qualitative research (2nd ed., pp. 455-486).Thousand Oaks, CA: Sage.

Thrift, N. (1994). Inhuman geographies: Landscapes of speed, light and power. In P. Cloke (Ed.), Writing the rural: Five cultural geographies (pp. 191-250). London: Paul Chapman.
Tribe, J. (2006). The truth about tourism. Annals of Tourism Research, 33, 360-381.

Unruh, D. R. (1980). The nature of social worlds. Pacific Sociological Review, 23(3), 271-296.

Uriely, N. (2009). Deconstructing tourist typologies: The case of backpacking. International Journal of Culture, Tourism and Hospitality Research, 3(4), 306-312.

Van Egmond, T. (2007). Understanding Western tourists in developing countries. Oxfordshire, UK: CABI.

Wacquant, L. (2005). Symbolic power in the rule of the "state nobility." In L. Wacquant (Ed.), Pierre Bourdieu and democratic politics: The mystery of ministry (pp. 133-150). Cambridge, UK: Polity.

Wenger, E. (1998). Communities of practice: Learning, meaning and identity. Cambridge, UK: Cambridge University Press. 